\title{
Novel Control Platform Development for PMLSM Based on Virtual Instrument
}

\author{
Jianxun Jin *, Wei Xu **, Yan Chen *, Youguang Guo *** and Jianguo Zhu *** \\ * School of Automation Engineering, UESTC, Chengdu, China \\ ** Platform Technologies Research Institute, RMIT University, Melbourne, Australia \\ *** School of Electrical, Mechanical and Mechatronic Systems Faculty of Engineering and Information Technology \\ University of Technology, Australia
}

\begin{abstract}
A novel control platform for the permanent magnet linear synchronous motor (PMLSM) drive system has been built up based on virtual instrument (VI) and related data acquisition card (DAQ) devices. In the traditional control platform, it mostly depends on digital signal processor (DSP), which needs a lot of time to further develop the interface between the personal computer (PC) and operators, and its computational capability is not strong than computer. To overcome these shortages, a novel control platform is presented on the base of one PC, one LabVIEW, and one multifunctional data acquisition card. Firstly, a space vector pulse width modulation (SVPWM) signal source is executed in the VI. Then in order to improve the precision of control system, the field oriented control (FOC) is proposed for the PMLSM. Finally comprehensive experiments verify with relative simulations.
\end{abstract}

Index Terms--PMLSM, SVPWM, FOC, LabVIEW, closed- Loop.

\section{INTRODUCTION}

Based on its notable advantages, such as high speed and high precision in long distance locations, high thrust force and reliability, permanent magnet linear synchronous motor (PMLSM) is widely used in servo drives. However, it is known that PMLSM is heavily influenced by mechanical parameter variations and external load disturbance in the drive process. In this case, a high precision control system is an indispensable component. For a traditional control platform of PMLSM, Digital Signal Processor (DSP) is the core of the control system, and it can get good excellent performance [1]-[3]. However, this kind of control platform has some disadvantages, such as spending too much time on developing the interface program between personal computer (PC) and DSP. If the displayed parameters of the system need to be changed, the program of PC interface should be rewritten. Besides, the computing capability of PC is rarely used in the hardware platform although PC has more computing capability than DSP. To overcome these drawbacks, a novel control platform based on virtual instrument (VI) is proposed in this paper. For the powerful graphical language in LabVIEW software, the development of this platform is easier than using DSP, which can change the ways collecting parameters expediently according to different practical situations. Compared with the DSP controlled platform, this kind of platform would get the same results with shorter developing cycles and more friendly interfaces.
Moreover, all the parameters can be displayed during the process of actual debugging duration.

This paper firstly introduces simulation models and results of field oriented vector control (FOC) of PMLSM though Matlab/simulation. Then, a space vector pulse width modulation signal source based on VI is introduced. In addition, compared with the simulation, one platform is developed using LabVIEW. Finally, a lot of measurements are presented to verify theoretical analysis.

\section{Simulation of Control System}

Fig.1 show the simulation module of control system based on FOC [4]. Thereinto, according to mathematical model of PMLSM, module of PMLSM is shown in Fig. 2, which includes "coordinate transformation", "balance of voltage", and "mechanical balance". Besides, module of SVPWM is shown in Fig. 3. The output of SVPWM is used to control inverter.

The parameters of designed PMLSM are: $M=10 \mathrm{~kg}$, $R=10 \Omega, B=0.1, \tau=45 \mathrm{~mm}, L_{\mathrm{d}}=L_{\mathrm{q}}=10 \mathrm{mH}$, and $\Psi_{\mathrm{f}}=0.5$ $\mathrm{Wb}$. The PWM period or called switching period $T_{\mathrm{s}}$ of SVPWM is $0.0001 \mathrm{~s}$, and the DC bus voltage of inverter is $280 \mathrm{~V}$.

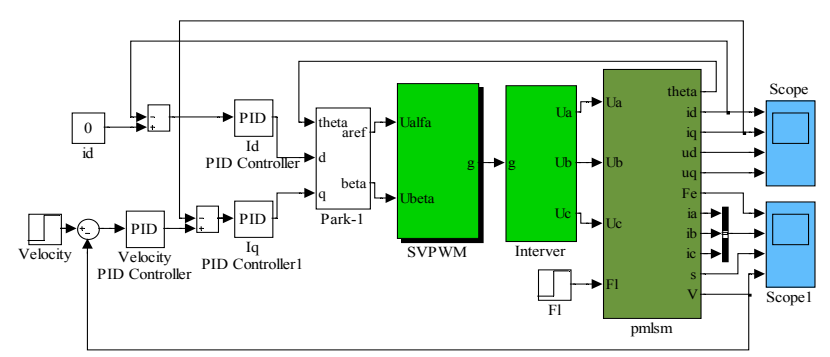

Fig. 1. The simulation module of control system.

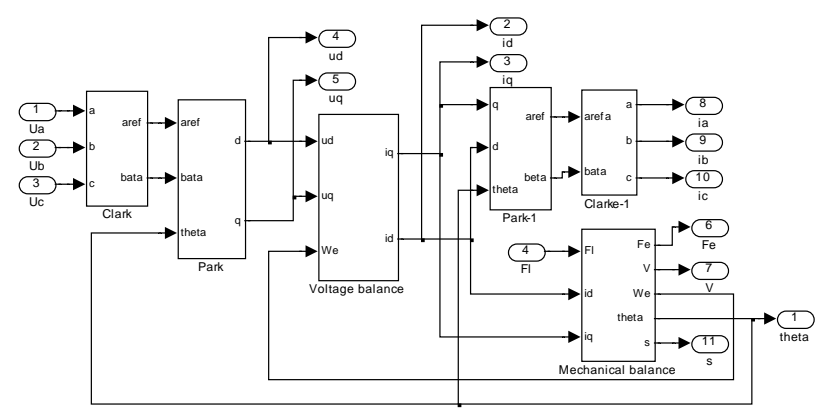

Fig. 2. The simulation module of PMLSM. 


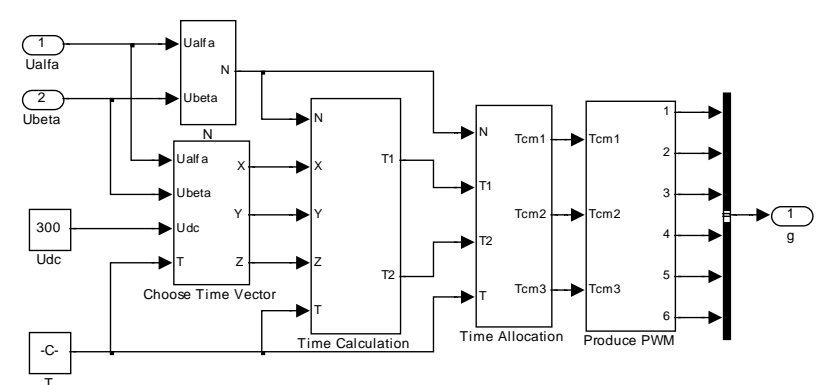

Fig. 3. The simulation module of SVPWM.

Fig. 4 shows the result of the simulation for the FOC system, and the starting velocity is set as $0.4 \mathrm{~m} / \mathrm{s}$. (a) is the three phase current during the operation of the motor. (b) is the speed of the mover under the set point. It has a good result of control system for needing little time to the set value and having no obvious fluctuate. (c) and (d) are the displacement and electrical angle of mover vs. time, respectively.

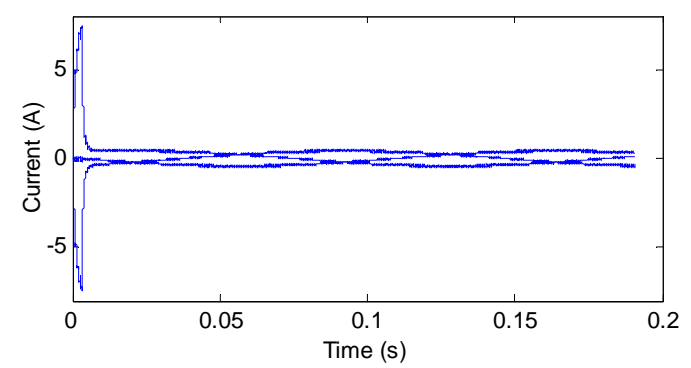

(a). Current

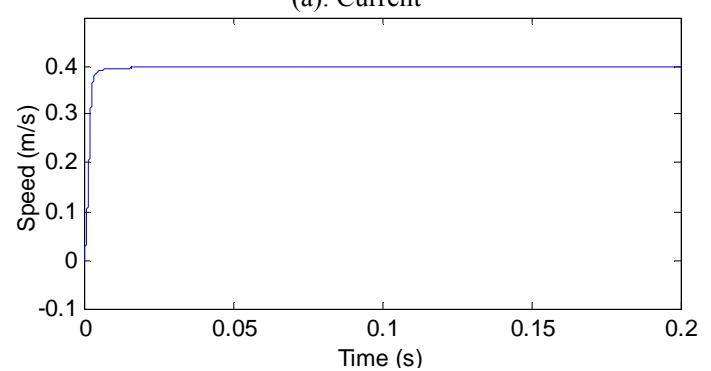

(b). Speed

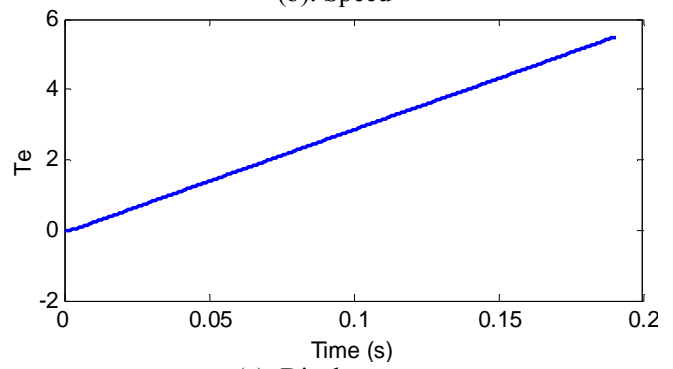

(c). Displacement

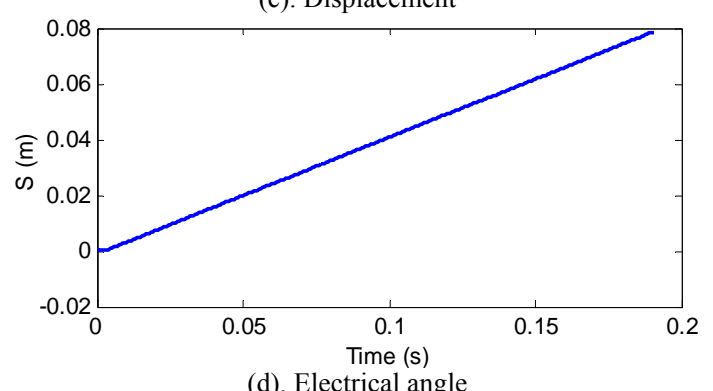

(d). Electrical angle

Fig. 4. The result of closed-loop control system.

\section{CONTROL System OF PMLSM}

The Structure of control and measurement system is shown in Fig. 5. This novel platform which is based on LabVIEW can drive PMLSM flexibility by choosing several parameters including velocity, displacement, direction of motion and period of SVPWM in the front panel of system. The entire process also can be displayed for operator in real-time.

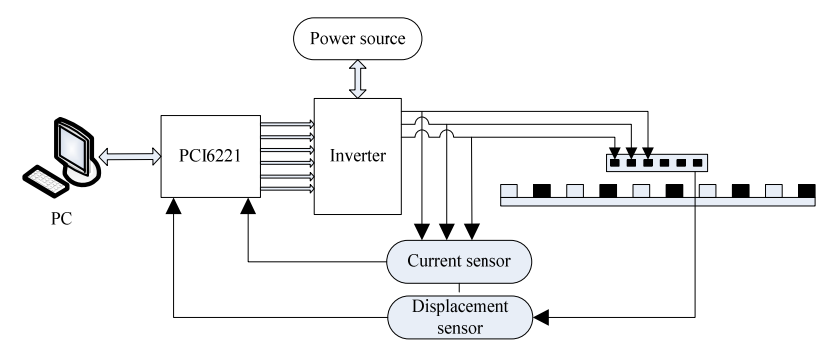

Fig. 5. Hardware structure of FOC system for PMLSM.

\section{A. Hardware of Platform}

The primary (stator) and secondary (rotor) of the PMLSM are composed of three-phase copper windings and permanent magnets, respectively. The moving short secondary includes $4 \mathrm{NdFeB}$ permanent magnets with alternate magnetic poles along moving direction and their back iron. The main parameters of the PMLSM are listed in Table I.

TABLE I

THE PARAMETERS OF PMLSM

\begin{tabular}{|l|l|l|}
\hline components & parameters & Value \\
\hline \multirow{4}{*}{ Stator } & Slot width & $20 \mathrm{~mm}$ \\
\cline { 2 - 3 } & Slot depth & $100 \mathrm{~mm}$ \\
\cline { 2 - 3 } & Slot number & 72 \\
\cline { 2 - 3 } & Tooth length & $10 \mathrm{~mm}$ \\
\cline { 2 - 3 } & Tooth width & $150 \mathrm{~mm}$ \\
\cline { 2 - 3 } & Tooth pitch & $30 \mathrm{~mm}$ \\
\hline \multirow{5}{*}{ Rotor } & PM length & $35 \mathrm{~mm}$ \\
\cline { 2 - 3 } & PM height & $15 \mathrm{~mm}$ \\
\cline { 2 - 3 } & PM width & $75 \mathrm{~mm}$ \\
\cline { 2 - 3 } & Thickness of PM back iron & $8 \mathrm{~mm}$ \\
\cline { 2 - 3 } & Polar pitch $\tau$ & $45 \mathrm{~mm}$ \\
\hline \multirow{5}{*}{ other } & Number of turns of coil winding & 120 \\
\cline { 2 - 3 } & Diameter of copper wire & $0.9 \mathrm{~mm}$ \\
\cline { 2 - 3 } & Resistance per phase & $1.4 \Omega$ \\
\cline { 2 - 3 } & Inductance per phase & $11.5 \mathrm{mH}$ \\
\hline
\end{tabular}

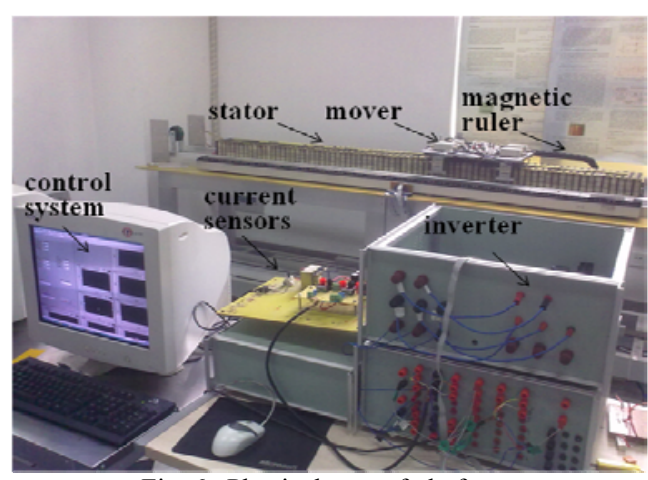

Fig. 6. Physical map of platform. 
Fig. 6 shows the Physical map of platform. Taking no account of PMLSM, the platform consists of "data collection", "data processing", and "control output". In "data collection", it has two kinds of sensors: magnetic ruler (GIVI MTS H25C), current sensors (Tamura L07P015A). For the magnetic ruler, the most difficult thing is how to install and correct the equipment as required. For the current sensors, low-pass filter of $\mathrm{RC}$ should be used before data acquisition (DAQ) card (PCI6221 ) get the three-phase current single, preferably.

"Data processing" is running in PC based on LabVIEW according to the algorithm of FOC. The core of platform is PC, which is getting the information of operation by analog input (AI) of PCI-6221 and output the single of SVPWM by digital output (DO) of PCI6221 .

\section{B. Software of Platform}

Fig. 7 shows the block diagram of field oriented vector control system. In this control system, stator current $i_{\mathrm{a}}, i_{\mathrm{b}}$ and $i_{\mathrm{c}}$ is measured using current sensor. Then they are transformed into $i_{\mathrm{q}}, i_{\mathrm{d}}$ in the $\mathrm{d}$-q frame through the Clarke and the Park transformation. After that, $i_{\mathrm{q}}, i_{\mathrm{d}}$ can be used as the negative feedback quantity of the electric current loop.

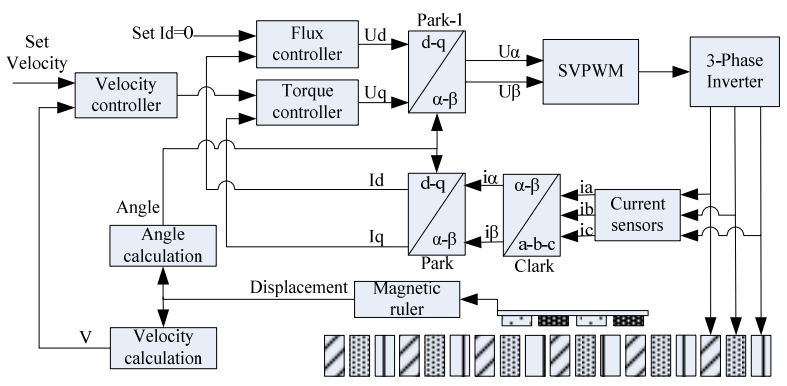

Fig. 7. Block diagram of FOC system.

The deviation between the given speed and the feedback speed $V$ is regulated through the velocity controller. The output is q axis reference component $i_{\text {qref }}$ to control the torque. The deviations between $i_{\text {qref }}, i_{\text {dref }}$ and current feedback quantity $i_{\mathrm{q}}, i_{\mathrm{d}}$ go through the flux and torque controller, and the respective output phase voltage $U_{\mathrm{q}}$ and $U_{\mathrm{d}}$. Then they are transformed into the stator phase voltage vector component $U_{\alpha}$ and $U_{\beta}$ through inverse Park transform. If the stator phase voltage vectors $U_{\alpha}$ and $U_{\beta}$ are known, we can use the SVPWM technique to produce PWM signal to control the inverter, so as to achieve closed-loop control of the PMLSM.

Fig.8 shows the flow chart of field oriented vector control system. For LabVIEW is a kind of software that can use multiple threads, the collection of current and displacement would proceed simultaneously. In the practice programming, there are have two frames in control system based on FOC The first one frame of while cyclic sentence in the block diagram is shown in Fig. 9. It has three functions: collecting current and displacement, the Clarke and Park transformation, PID control for speed and current. Fig. 10 shows the second one frame of while cyclic sentence in the block diagram.
According to $U_{\alpha}$ and $U_{\beta}$ which are calculated in the first frame, the main function of this part is produce SVPWM single.

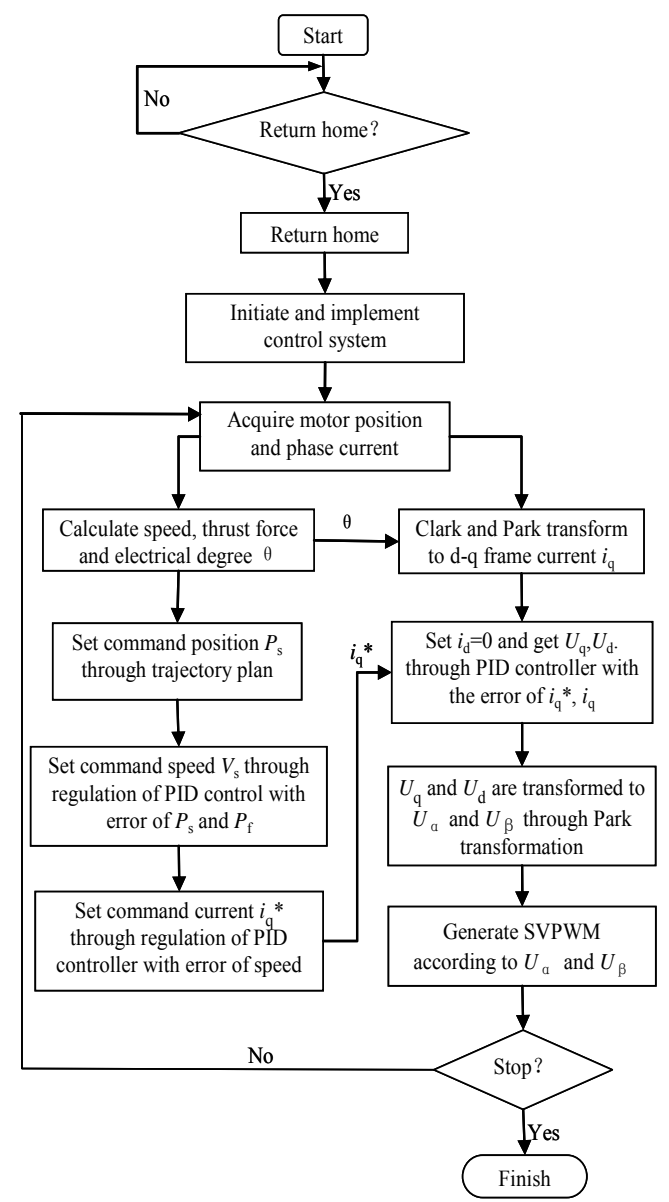

Fig. 8. Flow chart of field oriented vector control system.

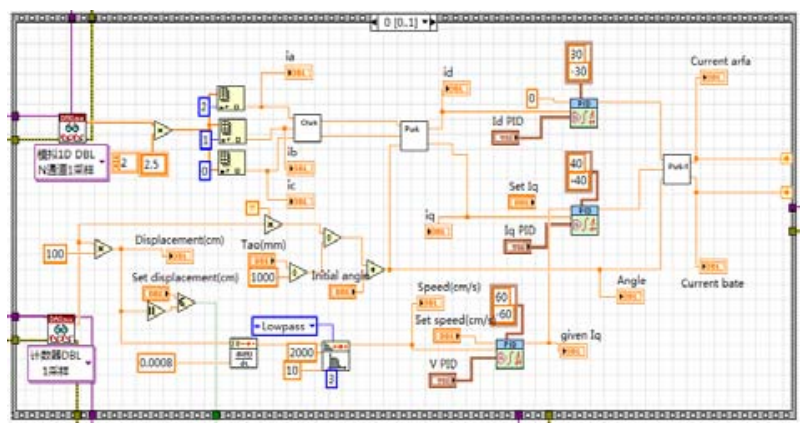

Fig. 9. First one frame of while cyclic sentence.

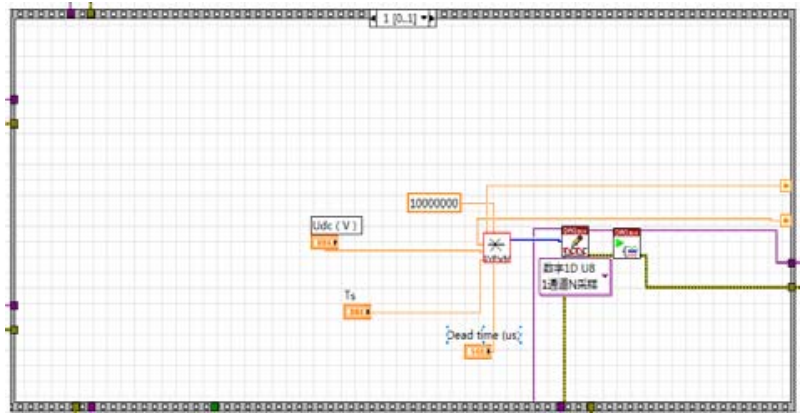

Fig. 10. Second one frame of while cyclic sentence. 


\section{Realization of SVPWM Based on LabVIEW}

This work mainly uses six DIO lines of PCI-6221 DAQ card to generate SVPWM signals. $10 \mathrm{MHz}$ external reference clock is selected as the DO sample clock. Regeneration mode is set as "Don't allow regeneration" to update the DO pattern on each rising or falling edge of clock signal. So the duration of high-level or low-level on DO lines is determined by the equation: $T_{\mathrm{Lev}}=A_{\mathrm{s}} / f$, where $A_{\mathrm{s}}$ is the array size of DO samples, $f$ is the frequency of DO sample clock. Accordingly the pulse width and period of the digital waveform can be controlled by the array size of DO samples.

Based on the principle of SVPWM, the software development of VI in LabVIEW include i) sector judgment; ii) choice of basic adjacent space voltage vectors; iii) calculation of operating time of basic vector; iv) sequence arrangement of basic vector; v) dead time inserting and vi) DO sample building. The flow chart of the software development is shown in Fig. 11 [5]-[7].

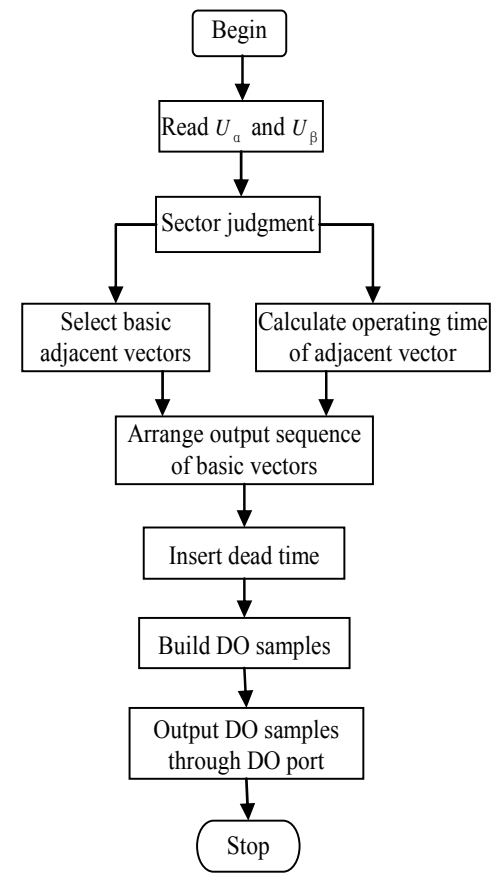

Fig. 11. Diagram of voltage space vector. Flow chart of SVPWM software development.

In sector judgment, (1) is used to determine the sector of reference voltage. Then the sector $P_{\mathrm{s}}$ which reference voltage is within can be decided by $P$, The relationship of them is listed in Table II. The block diagram of sector judgment in LabVIEW is shown in Fig. 12.

$$
\begin{aligned}
& P=\operatorname{sign}\left(U_{\beta r e f}\right)+2 \operatorname{sign}\left(\frac{\sqrt{3}}{2} U_{\text {oref }}-\frac{1}{2} U_{\beta r e f}\right) \\
& +4 \operatorname{sign}\left(-\frac{\sqrt{3}}{2} U_{\text {oref }}-\frac{1}{2} U_{\beta r e f}\right)
\end{aligned}
$$

TABLE II

SECTOR $P_{\mathrm{S}}$ VS. $P$

\begin{tabular}{|l|l|l|l|l|l|l|}
\hline$P$ & 1 & 2 & 3 & 4 & 5 & 6 \\
\hline$P_{\mathrm{s}}$ & 2 & 6 & 1 & 4 & 3 & 5 \\
\hline
\end{tabular}

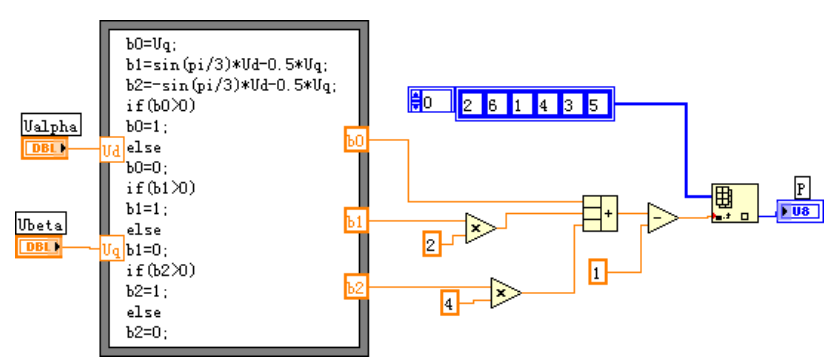

Fig. 12. Block diagram of "sector judgment. vi".

In choice of basic adjacent space voltage vectors, different sector has different non-zero basic adjacent voltage vectors. The relationship between them is shown in Fig. 13, which is the block diagram of selection of vector.

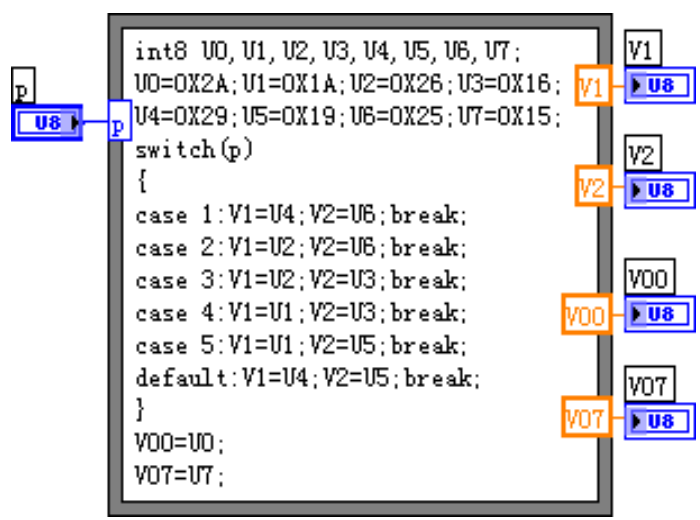

Fig. 13. Block diagram of "Selection of vector. vi".

Operating time of adjacent vector must be calculated out after selection of basic adjacent vector. As with the sector judgment, several intermediate variables are used to calculate the operating time. The block diagram of it in LabVIEW is shown in Fig. 14.

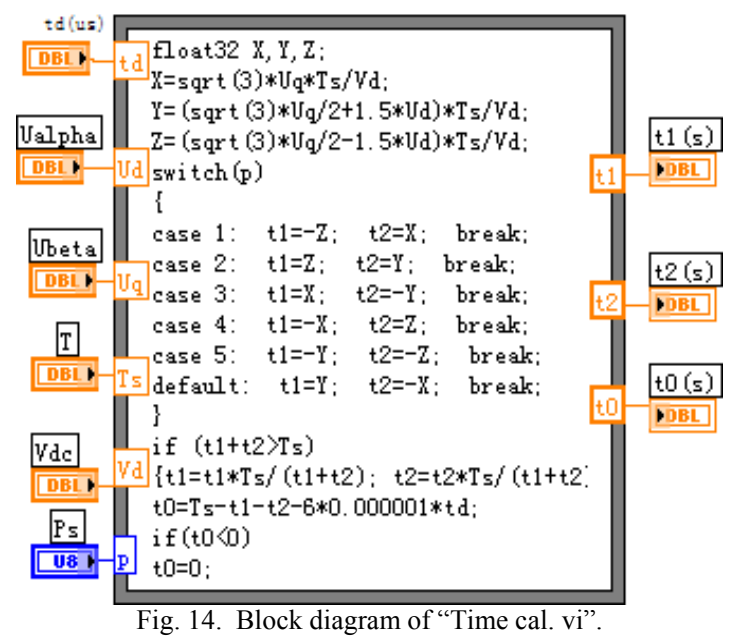

According to the rules about seven segments of SVPWM wave. The block diagram of operating time assignment is shown in Fig. 15. The outputs of the block are the divided operating time according to seven segments of SVPWM wave. 


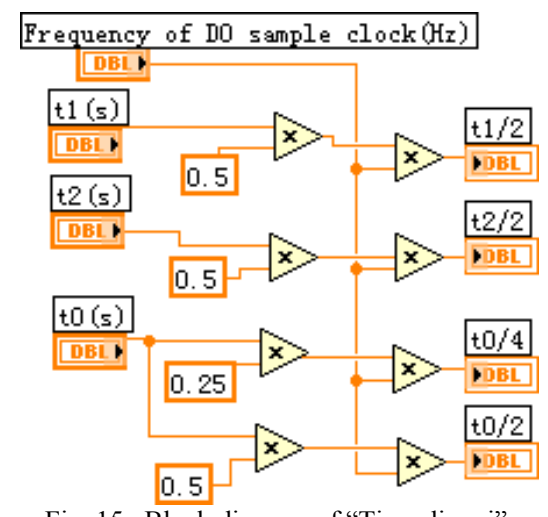

Fig. 15. Block diagram of "Time div. vi".

For the three-phase voltage source inverter, in order to avoid the short circuit of the DC link occurring when the two switch devices of the same phase are turned on simultaneously, the dead-vector $U \mathrm{~d}_{\mathrm{x}}$ and dead-time $t_{\mathrm{d}}$ must be inserted to the output sequence. The same method naturally can be used for other sectors, and $U \mathrm{~d}_{\mathrm{x}}$ can be calculated out by $U \mathrm{~d}_{\mathrm{x}}=U x \& \mathrm{U} y, t_{\mathrm{d}}$ can be set with any number by user. The block diagram of deadtime and dead-vector is shown in Fig. 16.

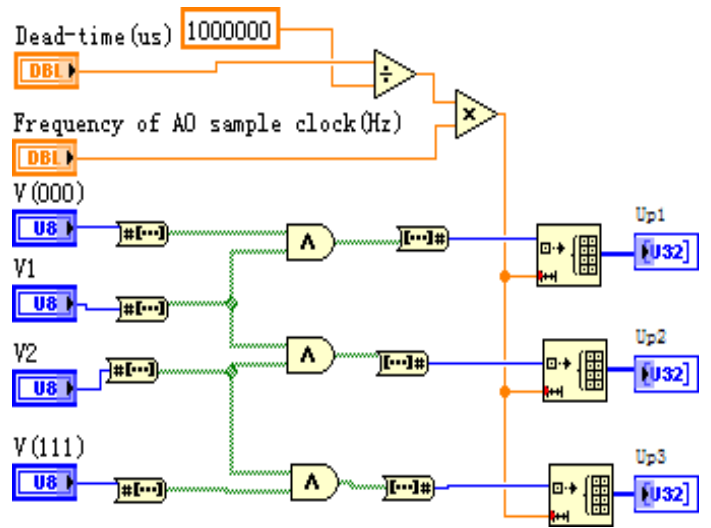

Fig. 16. Block diagram of "Dead-time and dead-vector. vi".

The whole block diagram of "SVPWM. vi" is shown in Fig. 17. The waveform of 3-phase output voltage of inverter is shown in Fig. 18. The colorized lines in the figure are the RMS of the output voltages. Their amplitude are $100 \mathrm{~V}$, frequency is $10 \mathrm{~Hz}$, with their phase difference of $120^{\circ}$. So the output voltage of inverter can be controlled by developed SVPWM module.

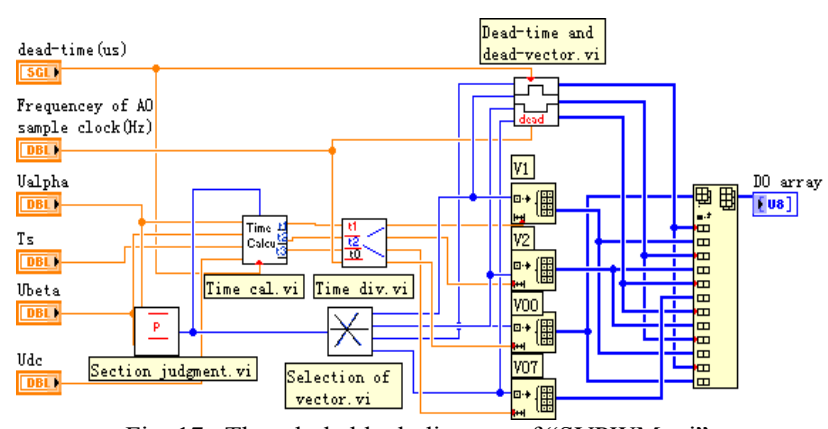

Fig. 17. The whole block diagram of "SVPWM. vi".

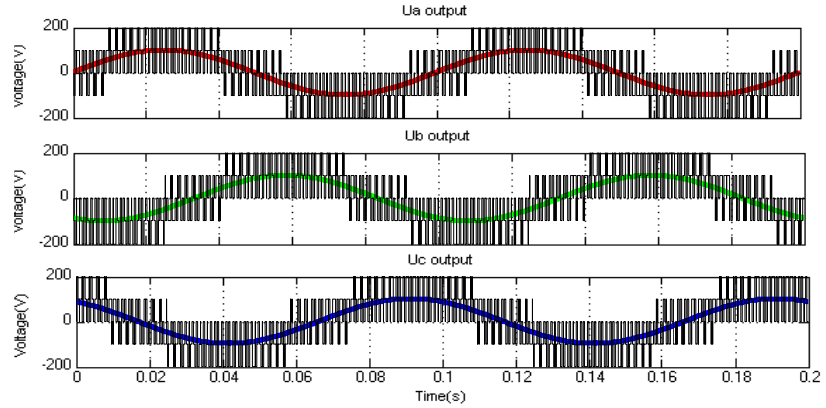

Fig. 18. Output voltage of the inverter.

\section{EXPERIMENT AND RESULT ANALYSIS}

An experiment of step speed response has been done to check the effectiveness of the proposed control system and algorithm. In this experiment, the set point of velocity is set as $0.4 \mathrm{~m} / \mathrm{s}$.

Fig. 19 is show the result of the experiment when the motor is running stably, (a) is the curve of velocity of the mover, it is exist a little oscillation phenomenon in velocity tracking response. The phenomenon is not perfect compare with the simulation of system, which is caused by end effect and the air gap is asymmetrical. In addition, the permanent magnet linear synchronous motor is developed by our laboratory independently. Core materials and the position of winding are also asymmetrical. Both of them make the control system become more difficulty. (b) and (c) are the result of displacement and electrical angle during the operation. Form the Figure, the curves of displacement and electrical angle are smoothly, which is one premise for operation effectively. Improve the measuring precision of displacement is one of most important way to get a precise control system. (d), (e), and (f) are the curves of 3 -phraes current during the operation.

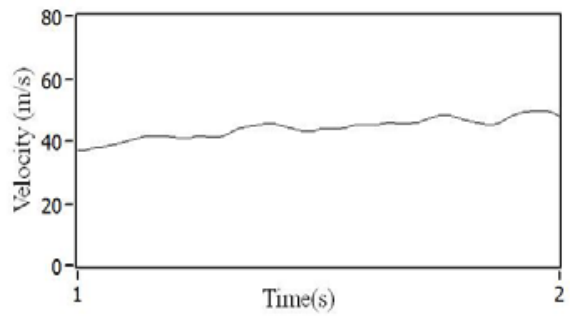

(a) Velocity

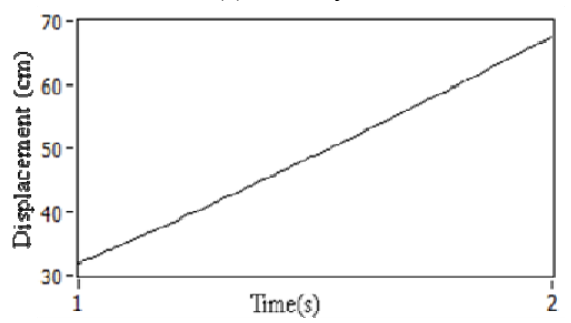

(b) Displacement 


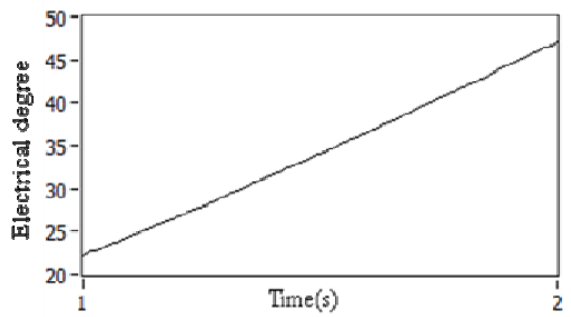

(c) Electrical angle

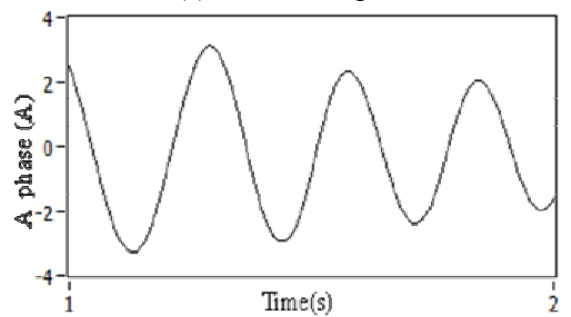

(d) A phase Current

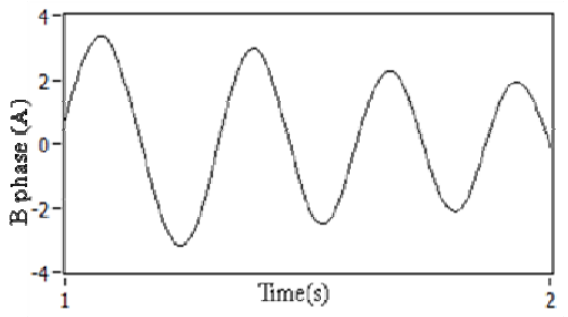

(e) B phase Current

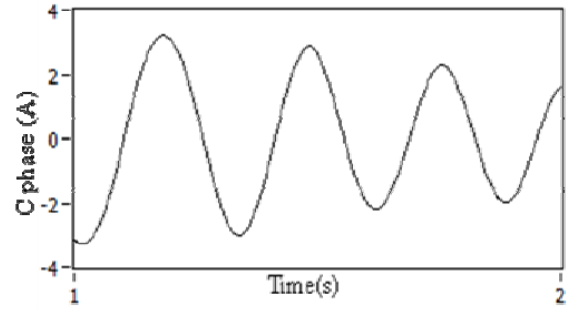

(f) $\mathrm{C}$ phase Current

Fig. 19. The experiment of step speed.

Fig.20 shows the curves of speed vs. number of date under various speeds setting value. In this figure, the date of $\mathrm{v}=20 \mathrm{~cm} / \mathrm{s}$ is got under $f_{\mathrm{pwm}}=0.5 \mathrm{kHz}$, while $\mathrm{v}=30 \mathrm{~cm} / \mathrm{s}$ is $1 \mathrm{kHz} . f_{\mathrm{pwm}}$ is the period of SVPWM. The influences of $f_{\text {pwm }}$ on the precision of speed are investigated by changing the $f_{\text {pwm }}$ from $0.5 \mathrm{kHz}$ to $1.25 \mathrm{kHz}$, which is shown in Fig.21. Increase the $f_{\text {pwm }}$ is one of effective ways to improve the precision of control system; however it demands strict hardware design. Taking many things into consideration, $f_{\mathrm{pwm}}$ is set as $1 \mathrm{kHz}$ in this platform. In this control system, one date is got in one PWM period.

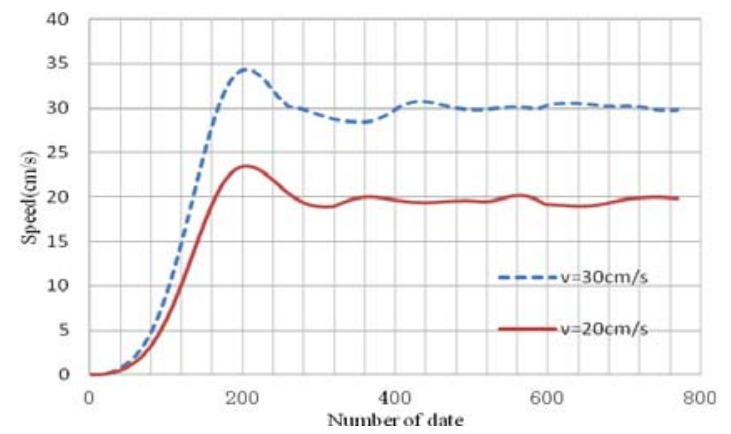

Fig. 20. The speed vs. number of date under various speed settings.

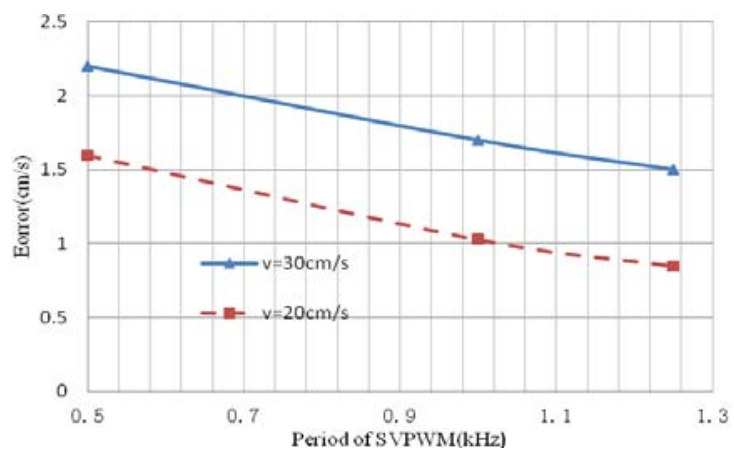

Fig. 21. The error of speed versus $f_{\mathrm{pwm}}$ under various speed settings.

\section{CONCLUSIONS}

In this paper, one new platform to execute the SVPWM technique for a 3-phase voltage inverter using a LabVIEW and a low cost multifunctional DAQ card has been built up. Afterwards, it further proposes a new speed controller considering the FOC algorithm for the PMLSM drive system base on VI. Compared with the traditional hardsware environment, the new platform demonstrates the following traits: i). the SVPWM technique based on LabVIEW can be widely used in the control system; ii). the control ability of the proposed control platform is effective; and iii). the platform proposed would get not only the same results but also a friendlier interface.

\section{REFERENCES}

[1] Y. S. Kung, "Design and Implementation of a HighPerformance PMLSM Drives Using DSP Chip," IEEE Transactions on Industrial Electronics, vol. 55, no. 3, pp. 1341-1351, March 2008.

[2] C. L. Wang, Y. D. Zhang, and L. Zhao, "Design of Vertical Transportation System Driven by Permanent Magnet Linear Synchronous Motor Signal Acquisition," 2012 International Conference on Industrial Control and Electronics Engineering, pp. 2033-2035, Aug. 2012.

[3] F. J. Lin, P. H. Chou, and C. S. Chen, "DSP-based synchronous control of dual linear motors via sugeno type fuzzy neural network compensator," 2011 International Conference on Electrical Machines and Systems, pp. 1-6, Aug. 2011.

[4] Y. W. Zhu, S. M. Jin, K. S. Chung, and Y. H. Cho, "Control-Based Reduction of Detent Force for Permanent Magnet Linear Synchronous Motor," IEEE Transactions on Magnetics, vol. 45, no. 6, pp. 2827-2830, June 2009.

[5] Z. G. Wang, J. X. Jin, Y. G. Guo, and J. G. Zhu, "SVPWM techniques and applications in HTS PMSM machines control," Journal of Electronic Science and Technology of China, vol. 6, no. 2, pp. 191-197, 2008.

[6] B. Vafakhah, J. Salmon, and A. M. Knight, "A New Space-Vector PWM With Optimal Switching Selection for Multilevel Coupled Inductor Inverters," IEEE Transactions on Industrial Electronics, vol. 57, no. 7, pp. 2354-2364, July 2010.

[7] S. Pan, J. M. Pan, and Z. H. Tian, "A Shifted SVPWM Method to Control DC-Link Resonant Inverters and Its FPGA Realization," IEEE Transactions on Industrial Electronics, vol. 59, no. 9, pp. 3383-3391, Sept. 2012. 